\title{
THROMBOSIS OF THE INFERIOR VENA CAVA.
}

By E. A. FRAYWORTH, M.D.

Male, aged 69, tea-taster, complained of a swollen leg.

History. Four days ago patient noticed swelling of the right leg commencing in the foot and spreading upward to the knee. This was painless at first but later there was some pain at night of a shooting character after sudden movements.

Past history. Rheumatic fever aged 23. ? nephritis aged 40. Phlebitis left $\stackrel{\infty}{\vec{O}}$ leg aged $5 \mathrm{I}$.

On examination. 30.7.37. Temperature $98.2^{\circ}$, pulse 62 , blood pressure 145-75. Patient was of small build. Dilated venules on face. Teeth, absent. Tongue, furred posteriorly. Tonsils, small. Neck, normal. Heart, slight enlarge- 3 ment both ventricles; soft systolic murmur audible at apex and base conducted $\vec{P}$ outwards to left axilla. Lungs, normal. Abdomen, liver palpable, $\frac{3}{4}$ inch below $\vec{v}$ right costal margin and tender. Spleen not palpable. Rectal examination, normal. Upper extremities, normal. Lower extremities, left, normal, except slight puffiness of ankle ; right, hard diffuse swelling below knee, skin shiny and pale, temperature not increased, circumference $\mathrm{I}_{\frac{1}{4}}$ inch more than left. Movements of joints normal.

Urine. Specific gravity, I020, acid, trace albumen.

Diagnosis. Morbius cordis with commencing decompensation; phlebitis right产 leg; congestion of liver.

Treatment. Patient was put to bed with the right leg elevated on a pillow and $\overrightarrow{0}$ given radiant heat to leg twice daily. He was also given :-

Liq. ammon. acet., $m \times x x$.

Sp. æth. nit., mxv.

Tr scillæ, mxv.

Vin. colchici, mxv.

Aqua chloroform, ad 3 fs., t.d.s., p.c.

Intravenous injections of 5 c.cs. Ca-Br-lactobionate were given daily.

Course of illness. After treatment for 7 days the patient was practically well. A blood count showed the following:-

Red blood cells, 3,700,000.

White blood cells, 8,400.

Hæmoglobin, 60 per cent.

Colour index, 0.85 .

An X-ray of the right foot was normal. Eight days later both legs became stiff with swelling of both ankles, more marked on the right side, but the following day the swelling of the right leg increased up to the knee and it became painful. The tips of the right toes showed congestion. Later the left leg became swollen and thrombosis of the right saphenous vein was noticed. After further rest in bed the swelling of the legs decreased somewhat. His condition remained stationary until 12.9.37-six weeks after the onset of the illness - when the right lower extremity became suddenly swollen as far as the groin and the toes became livid and cyanosed. The left lower extremity became swollen as far as a point I inch above the knee joint. Intravenous injections of theophyllin, ro c.cs. of Io per cent. solution, were given twice daily for three days. On I6.9.37 the right lower extremity was very large and the swelling of the left reached to the groin. 
Southey's tubes were inserted and several pints of fluid were removed each day. It was noticed that there was no œdema of the scrotum.

On 23.9.37 the patient became delirious and euphoric for several hours. On 25.9.37 both superficial epigastric veins became dilated and palpable. The œedema had spread to the gluteal region, the crest of the ilium and lower part of the abdomen. On 28.9.37 the pulse became irregular and his mentality was confused. On 29.9.37 he died in coma. Just prior to death both legs became bluish-black.

Post-mortem examination. Abdomen only. The peritoneal cavity contained 2-3 pints of turbid fluid. Intestines, normal. Liver, enlarged and contained deposits of neoplasm. The visceral and parietal peritoneum contained numerous deposits of neoplasm. Stomach, nodule size of small walnut in posterior wall of prepyloric region. The gall bladder was thickened, the size of a hen's egg and contained one large stone. The inferior vena cava was compressed between the gall bladder and the vertebral column and contained a long laminated thrombus from its origin to the entrance of the renal veins. The right and left iliac veins were thrombosed.

Microscopical examination of the nodule in the stomach showed an adenocarcinoma and the masses in the liver proved to be secondary adeno-carcinoma. 